\title{
La función probatoria del documento público y privado en los tipos penales de falsedad documental*
}

\section{The probative function of public and private documents in the criminal types of documentary falsification}

\section{Laura Andrea Acosta Zárate ${ }^{* *}$, Ricardo Hernán Medina Rico ${ }^{* * *}$}

\begin{abstract}
* El presente artículo hace parte del proyecto de la línea de investigación en problemas actuales del Derecho Penal del Grupo de Investigación en Derecho Penal de la Universidad del Rosario

**Abogada, con profundización en Derecho Penal. Especialista en Ciencias Penales y Criminológicas. Magíster en Sistema de Justicia Penal Fiscalías Delegadas ante la Corte Suprema de Justica. Profesora de Constitución Política y Democracia en la Universidad del Rosario.

***Abogado, especialista en Derecho Penal y en Derecho Administrativo. Magíster en Justicia Criminal. Profesor de pregrado y posgrado en la Universidad del Rosario.
\end{abstract}

Cómo citar: Acosta, L.A., Medina, R.H. (2017) La función probatoria del documento público y privado en los tipos penales de falsedad documental. Inciso, 19(1): 33-47.

Recibido:07/10/2016 Revisado: 22/02/2017 Aceptado: 20/06/2017

\section{Resumen}

El presente texto busca abordar la existencia del documento como medio probatorio y las implicaciones jurídico penales de plasmar falsedades en los mismos a partir de un análisis de fuentes del derecho tales como la jurisprudencia y la doctrina y una revisión normativa bajo un estudio de la veracidad y la autenticidad como principios fundantes de la importancia del escrito. A partir de ello se presenta la definición de este medio probatorio en el sistema normativo vigente y cuáles son los elementos del mismo así como la distinción entre uno de carácter privado y aquel proferido por una entidad estatal. También se realiza un análisis sobre la mendacidad y el artificio - ya sea en la veracidad o en la autenticidad - del documento y se resolverá a la cuestión de si cualquier tipo de alteración a la verdad conlleva a la comisión de algún tipo de punible o si por el contrario existirán circunstancias que no sean del tenor de la justicia penal colombiana. Lo anterior permite concluir, al finalizar el texto, que no todo engaño plasmado en un papel conlleva a un delito de falsedad pero en el evento de existir una falta sobre la verdad, ya sea material o ideológica, y este documento tenga relevancia en el tráfico común de las cosas, implicará las sanciones previstas en el Código Penal Colombiano.

Palabras clave: Derecho Penal, Falsedad, Documento, Prueba, Tipicidad.
The present text seeks to address the existence of documents as means of evidence and the criminal legal implications of implanting falsehoods in them, from an analysis of sources of law such as jurisprudence and doctrine and a normative review under a study of truth and authenticity as founding principles of the importance of a written document. From this, it is presented the definition of this means of proof in the current normative system and what are the elements of the same, as well as the distinction between one of private character and the one pronounced by a state entity. An analysis is also made of mendacity and artifice - whether in the veracity or authenticity - of the document, and it will be solved to the question of whether any kind of alteration to the truth leads to the commission of some type of punishable (act); or if on the contrary, there will be circumstances that are not of the tenor of the Colombian criminal justice. This allows us to conclude, at the end of the text, that not every deceit implanted in a paper leads to a crime of falsehood; but in the event of a lack of truth, whether material or ideological, and that this document has relevance in trafficking common ground of things, it will involve the penalties provided for in the Colombian Penal Code.

Key words: Criminal Law, Falsehood, Document, Test, Typicality. 


\section{Introducción}

El mundo en que se desarrolla la sociedad actual se edifica a partir de las relaciones humanas. Con ellas, miles de comportamientos ejemplifican la simplicidad del hombre en ocasiones tan real y autóctono como la verdad, y en otras, tan falaz y oscuro como una mentira. En un mundo moderno como el que vivimos, el faltar a una promesa ya no solo cala en lo más profundo de un corazón roto sino que por el contrario hoy en día la desconfianza se ha convertido en derrotero del actuar del ser humano.

De esta manera, se han dejado de lado aquellos escenarios de épocas pretéritas en donde el simple acuerdo de voluntades - con la palabra como garante y la honestidad como testigo conllevaba a que se cumpliera lo pactado, para pasar a una realidad en donde la palabra dejó de ser fiable y el honor pasó de ser encubridor de estafas. Por ello, se buscó la forma de inmortalizar esa expresión de la voluntad, dotando de significativa importancia a la escritura como herramienta para la protocolización de la verdad.

Esta incipiente necesidad dio lugar a que el documento se convirtiese en el mecanismo perfecto para que las relaciones sociales y jurídicas encontraran un sustento, encarnando desde su mismo origen una de las funciones más importantes de este elemento y la cual será desarrollada a lo largo de este texto: la función probatoria.

En consecuencia de lo anterior se analizará a continuación la problemática que se desarrolla a partir de la tipificación de tipos penales tales como la falsedad material o ideológica en documento público o privado y los límites existentes entre la denominada mentira piadosa y aquella que conlleve consecuencias jurídicas del talante de la pena privativa de la libertad.

\section{Una nueva problemática}

El documento, como se anotó en la introducción, no está reservado únicamente para la constatación de las relaciones entre particulares, por el contrario, al ser una herramienta de prueba, ha ocupado una posición predilecta a la hora de la materialización de algunos negocios jurídicos, así como de las expresiones de voluntad de la administración; de esta manera, este medio probatorio consigue un estatus que no había tenido hasta el momento, pues es la misma institucionalidad del Estado la que dota al documento de una calidad casi inmaculada, en donde la verdad responde a la manifestación de la fe pública.

Ahora bien, a pesar de la tranquilidad generada a partir de la consagración en físico de la palabra, la sociedad del riesgo que cambia y se adecúa a los estándares de protección, ha generado en las mentes criminales formas de alterar, suprimir y destruir los documentos. Las finalidades son innumerables y ha llevado a que el último escalón de control social - el Derecho Penal tenga que intervenir para prevenir la comisión de estos hechos o para sancionar y castigar los ya cometidos.

Por ello, legislaciones como la ecuatoriana y la colombiana han contemplado como delitos la falsedad en documentos o la utilización de documentos falsos. Ambos ordenamientos jurídicos consideran estas conductas como atentatorias contra el bien jurídico de la fe pública. De esta manera, la sección novena del Código Orgánico Integral Penal de la República del Ecuador, así como el Título noveno del Código Penal de la República de Colombia se titulan de la misma forma: "Delitos contra la Fe Pública".

En este sentido, el estatuto penal de la Republica ecuatoriana en su artículo 328 contempla estas conductas reprochables, a saber: 
Artículo 328. Falsificación y uso de documento falso. La persona que falsifique, destruya o adultere modificando los efectos o sentido de los documentos públicos, privados, timbres o sellos nacionales, establecidos por la Ley para la debida constancia de actos de relevancia jurídica, será sancionada con pena privativa de libertad de cinco a siete años.

Cuando se trate de documentos privados la pena será de tres a cinco años.

El uso de estos documentos falsos, será sancionado con las mismas penas previstas en cada caso.

por su parte, los artículos 286, 287, 288 y 289 de la Ley 599 de 2000 o Código Penal de Colombia establecen la falsedad en documento público (ya sea ideológica o material), la obtención de documento público falso y la falsedad en documento privado respectivamente, de la misma manera, sanciona la utilización de documentos falsos en el artículo 291. El ordenamiento jurídico colombiano también penaliza la destrucción, supresión u ocultamiento de documento público o privado en los tipos penales consagrados en los artículos 292 y 293. Veamos:

Artículo 286. Falsedad ideológica en documento público. El servidor público que en ejercicio de sus funciones, al extender documento público que pueda servir de prueba, consigne una falsedad o calle total o parcialmente la verdad, incurrirá en prisión de sesenta y cuatro (64) a ciento cuarenta y cuatro (144) meses e inhabilitación para el ejercicio de derechos y funciones públicas de ochenta (80) a ciento ochenta (180) meses.

Artículo 287. Falsedad material en documento público. El que falsifique documento público que pueda servir de prueba, incurrirá en prisión de cuarenta y ocho (48) a ciento ocho (108) meses.

Si la conducta fuere realizada por un servidor público en ejercicio de sus funciones, la pena será de sesenta y cuatro (64) a ciento cuarenta y cuatro (144) meses e inhabilitación para el ejercicio de derechos y funciones públicas de ochenta (80) a ciento ochenta (180) meses.

Artículo 288. Obtención de documento público falso. El que para obtener documento público que pueda servir de prueba, induzca en error a un servidor público, en ejercicio de sus funciones, haciéndole consignar una manifestación falsa o callar total o parcialmente la verdad, incurrirá en prisión de cuarenta y ocho (48) a ciento ocho (108) meses.

Artículo 289. Falsedad en documento privado. El que falsifique documento privado que pueda servir de prueba, incurrirá, si lo usa, en prisión de dieciséis (16) a ciento ocho (108) meses.

Artículo 291. Uso de documento falso. El que sin haber concurrido a la falsificación hiciere uso de documento público falso que pueda servir de prueba, incurrirá en prisión de cuatro (4) a doce (12) años.

Si la conducta recae sobre documentos relacionados con medios motorizados, el mínimo de la pena se incrementará en la mitad.

Artículo 292. Destrucción, supresión $u$ ocultamiento de documento público. El que destruya, suprima u oculte total o parcialmente documento público que pueda servir de prueba, incurrirá en 
prisión de treinta y dos (32) a ciento cuarenta y cuatro (144) meses.

Si la conducta fuere realizada por un servidor público en ejercicio de sus funciones, se impondrá prisión de cuarenta y ocho (48) a ciento ochenta (180) meses e inhabilitación para el ejercicio de derechos y funciones públicas por el mismo término.

Si se tratare de documento constitutivo de pieza procesal de carácter judicial, la pena se aumentará de una tercera parte a la mitad.

Artículo 293. Destrucción, supresión y ocultamiento de documento privado. El que destruya, suprima u oculte, total o parcialmente un documento privado que pueda servir de prueba, incurrirá en prisión de dieciséis (16) a ciento ocho(108) meses.

Caben entonces una serie de preguntas tales como, ¿cualquier tipo de alteración genera una falsedad? ¿Cualquier falsedad contentiva en un documento activa la acción penal? ¿Una denominada "mentira piadosa" elevada a documento es constitutiva de delito?

No toda acción que desencadene en la falsedad de un documento eleva a la categoría de delito la conducta desplegada por el agente. El sujeto que por medio de un sofisticado programa de computadora crea un diploma para colgarlo en su cuarto y alardear de sus títulos no comete falsedad si solo lo tiene de decoración. La particular que cambia la foto de su pasaporte porque considera que la que tiene el documento la hace ver mucho mayor quizás no cometa el delito que aquí se estudia. La pareja de enamorados que se escribe cartas de amor y en ella consagra un sinfín de expresiones que bajo la óptica de la realidad son falsas no genera conducta delictiva. Debe existir entonces un límite para poder determinar cuándo hay falsedad y cuándo este tipo de modificaciones son propias del ámbito personal y la jurisdicción no puede cohibirlas.

Por lo anterior, el presente texto pretende fijar de manera concisa el límite existente entre una conducta constitutiva de delito y una que no hace parte de la órbita penal. Para ello, se expondrá lo que en Colombia se ha configurado como "función probatoria", la cual deben tener todos los documentos para que su falsedad sea constitutiva de delito, cuestión que en el nuevo código ecuatoriano podría englobarse en la expresión "actos de relevancia jurídica" que contiene su articulado normativo.

Cada vez que la expresión falsedad documental es pronunciada, lo primero que salta a la mente, es la materialidad de un documento; no obstante en pocas ocasiones, se da desarrollo a cada una de las funciones, clases e incidencias que tienen estos objetos en la vida cotidiana y en especial en la vida jurídica, por tal razón, se hace imperativo dar desarrollo a la función probatoria del documento tal y como se anticipó en acápites anteriores, para así, resaltar la relación que existe entre ésta con los documentos tanto públicos como privados y los delitos de falsedad documental.

\section{Elementos del documento}

Para poder dar solución al tema propuesto, es necesario disgregar cada uno de los elementos previstos en el postulado, para así poder apreciarlos por separado, lo que facilita su análisis en conjunto. En este sentido, en un primer momento, se hará alusión al concepto de documento, su función probatoria, el documento de carácter publico y privado y finalmente la relación que existe ente estos y los tipos penales previstos en el capitulo tercero del Código Penal Colombiano.

De conformidad con lo anterior, es necesario hacer referencia en un primer momento al 
concepto de documento, por tal motivo, la doctrina se ha encargado de recopilar las diferentes acepciones que se le han dado a esta definición señalando:

"En sentido etimológico, documento procede de la palabra latina documentum que, a su vez, viene de docere que significa enseñar $o$ transmitir algo. Siguiendo al Profesor López Yepes, vemos que en el latín medieval documentum tiene un sentido de enseñanza $y$ de precepto moral. Con este sentido pasa al castellano antiguo, significando "enseñamiento, doctrina o consejo". Alonso de Palencia en su Vocabulario Universal (1940) nos dice que: "documenta son exemplos para saber e semeiança para que meior entiendan". Este contenido semántico perdura en nuestra lengua a través de los siglos, aceptándose posteriormente también la significación de instrumento de prueba, asi lo hace el Diccionario De La Lengua en su quinta edición (1813). El diccionario ideológico de Julio Casares entiende por documento estas acepciones: "instrucción o consejo que se da a uno en cualquier materia acredita o hace constar una cosa. Figuradamente cualquier cosa que sirve de prueba". Las palabras derivadas: Documentar y documentación, se han ido incorporando posteriormente con el sentido de "probar la verdad de una cosa con documentos", "conjunto de documentos que sirve para el fin de documentar" (Martos, 2005: 249).

Apelando a la definición misma, autores como Antonio José Martínez López, se refieren al concepto de documento como:

"La acepción de dicha palabra en el idioma respectivo o sea un escrito que sirve para probar o enseñar sobre algo. La esencia del documento es su contenido histórico-informativo (...) lo importante es que el documento contenga una expresión o manifestación de persona, cualquiera sea la finalidad con que se hizo" (Martínez, 1995: 35).
De lo anterior se colige que, en sí mismo el documento no solo es un instrumento de instrucción o reproducción de información, sino que se entiende como todo objeto apto para utilizarlo como medio probatorio y del cual, se derivan características tan importantes como lo son: (i) que el documento responda a la manifestación de la voluntad de un individuo, (ii) que de éste se pueda reputar su autenticidad y (iii) que el documento revista una condición especial que no es otra que la de la formalidad escrita.

El primer elemento enunciado es quizás uno de los más importantes teniendo en cuenta que, debe ser entendido como aquella motivación que conlleva a la consecuente elaboración del documento. Sin lugar a dudas, el querer dar a conocer una voluntad, pero en especial, la intención de dejar una constancia de ese querer consciente hace que los seres humanos construyan documentos en cualquiera de sus acepciones. El documento entonces es ese vehículo que incorpora la voluntad de quien lo suscribe y se encarga de cumplir una serie de funciones -las cuales serán desarrolladas con posterioridad-, ante la sociedad.

Aunado a esta primer condición, es importante resaltar que no es suficiente que:

"La manifestación de la voluntad o
expresión provenga de persona. Es
necesario además que esa expresión sea
entendible, comprensible, inteligible.
Sólo si posee esta cualidad puede tener
trascendencia en el campo de las relaciones
jurídicas. Un escrito ininteligible jamás
podrá tener importancia en materia de
falsedad, por cuanto es incapaz de producir
consecuencias en el campo de las relaciones
materiales estudiadas, que constituyen la
razón de ser de la protección del documento
y de la fe pública" (Arenas, 2015: 326).


La segunda cualidad del documento anteriormente enunciada, hace alusión al sujeto que elabora este objeto, lejos de enfatizar en las condiciones propias de la persona, esta condición del documento se refiere a la esencialidad de saber que fue ésta y no otra quien realmente lo fabricó. Ampliamente la doctrina se ha ocupado de este elemento, coincidiendo en que la autenticidad se presenta como:

"La certeza que se tiene, respecto del documento, de que procede de la persona que lo ha elaborado o firmado. Se debe entender el vocablo "elaborado" en el sentido de la persona que ha hecho la "manifestación" objetivada en la forma de que se trate, y la persona que ha hecho la misma. De ahi que se hable de autenticidad material y de autenticidad formal, la del contenido y la de la forma. Documento autentico es, pues, aquel que no admite duda respecto a la certeza sobre su autor" (Irureta, 1992: 35).

Al tenor de lo expuesto, vale la pena resaltar que todas las declaraciones que se inmortalizan en un documento más allá de los efectos que generan sobre este - como se verá más adelante-, pueden provenir de cualquier persona, sin importar su calidad, lo importante en este caso es, que quien elabora el documento sea una persona conocida o conocible, en este punto es válido señalar que:

\begin{abstract}
"El legislador colombiano, muy acertadamente, empleó los términos conocido o conocible, pues bien puede ocurrir que el autor no pueda ser plenamente identificado pero si susceptible de identificar" (Cancio, 1981: 165).
\end{abstract}

Por su parte, la última característica que se le endilgó al documento fue la escrituralidad, en este punto es necesario advertir que esta condición no es producto de la modernidad ni de la desconfianza como común denominador de las relaciones sociales, por el contrario:

\begin{abstract}
"el carácter escrito de una declaración frente a una declaración oral- no significa una mayor garantía de verdad. En otra época quizás no fue así, cuando la forma escrita era el medio de manifestación de la gente docta; pero la autoridad de lo escrito se fundamentaba precisamente en la autoridad del escritor (o, en el caso de las Sagradas Escrituras, en la autoridad de Dios, que se servía del escritor) y, por ello, eso era asi también para la palabra hablada bajo condiciones que resaltaban a la persona hablante (bien sea porque hablaba desde el púlpito o bien porque lo hacia abajo juramento). La autoridad, por lo tanto, era consecuencia de la posición destacada del autor, y no sólo por el hecho del carácter escrito" (Jakobs, 2011: 67).
\end{abstract}

Sin embargo, es preciso hablar de esta en tiempo pasado, pues con el pasar de los años, el documento ha adoptado formas distintas con la que se previó originalmente. Al respecto se ha señalado:

"En efecto, mientras en la doctrina se sostenía que el documento requiere la forma escrita y que no merecerán la consideración de documento los objetos que, aunque materialicen la manifestación de un pensamiento no adopten la forma escrita, la jurisprudencia se hizo cargo de la evolución de la técnica y la aparición de nuevos soportes documentales, ampliando de esta manera el concepto de documento y desligándolo de la exigencia de la escritura" (Bacigalupo, 1999: 11).

Por su parte otros autores señalan que el documento posee unas funciones tales como:

En primer lugar, diremos que quien crea un documento busca con ello tres cosas, primero, perpetuar el pensamiento que quiere transmitir (función de perpetuidad que no es eternidad), y crear en quienes conozcan el contenido del documento alguna percepción. Quienes acceden al documento, 
podrían entonces comprender las ideas de quien las plasmó en el documento y de allí que las mismas puedan serle atribuidas a su creador (en segundo lugar, función de garantía). Adicionalmente, en la medida en que el documento debe ser introducido al tráfico jurídico, debe tener la capacidad de probar situaciones con relevancia jurídica -función probatoria, que será la tercera finalidad que se encuentra presente en quien crea un documento-. En un criterio que no compartimos, SCHILLING adiciona una cuarta función al documento que denomina función de ayuda en virtud de la cual el documento se encuentra al servicio del tráfico económico y de la ejecución de derechos jurídicos" (CASTRO, 2012: 653)

Una vez revisadas las principales características del documento, es necesario identificar el concepto puntual de este objeto, por tal motivo, a continuación se puntualizará respecto de la definición de documento, sus diferentes variedades y el tratamiento que se le ha dado en Colombia a través de los diferentes medios legales y doctrinarios.

\section{El documento}

Es necesario advertir que pese a algunas apreciaciones ligeras, documento no es solo aquel que reposa en un papel o que se ve materializado en unas letras impresas sobre una hoja, recientemente, se ha establecido que la calidad de documento abarca un abanico mucho más amplio, enfatizando que dicho objeto material, podrá fungir como documento siempre que tenga la capacidad de representar o declarar un cuestión.

Es por esto que la normatividad colombiana, en especial la Ley 906 de 2004, se ha ocupado de compilar aquellos documentos que tienen la función de servir de prueba de la siguiente manera:
“Artículo 424. Prueba documental. Para los efectos de este código se entiende por documentos, los siguientes:

1. Los textos manuscritos, mecanografiados o impresos.

2. Las grabaciones magnetofónicas.

3. Discos de todas las especies que contengan grabaciones.

4. Grabaciones fonópticas o vídeos.

5. Películas cinematográficas.

6. Grabaciones computacionales.

7. Mensajes de datos.

8. El télex, telefax y similares.

9. Fotografias.

10. Radiografias.

11. Ecografias.

12. Tomografias.

13. Electroencefalogramas.

14. Electrocardiogramas.

15. Cualquier otro objeto similar o análogo a los anteriores".

Más allá de la clasificación de los diferentes medios probatorios enunciados, previstos como acepciones del documento, es imperativo destacar las diferentes funciones que cumple este, con tal propósito, es necesario hacer referencia a la obra del doctor José Antonio Vega Vega, "El documento jurídico. Problemas de la electrificación", en cuanto indica:

"Podemos afirmar que el documento está encaminado principalmente a dos fines: uno de trascendencia informativa o histórica, esto es, como fuente de datos o registros que ilustra acerca de algún hecho acaecido en el pasado histórico, o sobre el cual deben tenerse en cuenta ciertos resultados. Tendría en este caso una función de archivo o recopilación de hechos para su transmisión o consulta. En un segundo sentido tendría una función más específicamente jurídica. podría considerarse como el soporte en el que constan datos fidedignos y susceptibles 
de ser empleados para probar o dar a conocer algún hecho relevante para el mundo del Derecho" (Vega, 2013: 145 192). (Énfasis suplido)

No obstante, la finalidad de información y su carácter probatorio no son las únicas calidades que puede tener un documento, es por esto, que en este punto es necesario hacer una breve mención de cada una de estas. Veamos:

Una de las características que debe tener todo documento es la inteligibilidad, es decir, "que sea susceptible de ser comprendido por el intérprete o interesado que se acerca a captar la información o los datos contenidos en el mismo" (Vega, 2013: 151). No basta con que la información esté plasmada en el documento, sino que además, es necesario que quien tenga acceso a él pueda identificar el contenido del mismo para que así eventualmente pueda utilizarlo.

Conforme a lo anterior, el documento debe tener aptitud para determinar la convicción de su destinatario, lo que indica que quien posee un documento, debe creer al menos que su contenido responde a la realidad:

"cuando hablamos de contenido cierto, no exigimos que el documento se ajuste a la verdad, esto es, que su contenido sea veraz, sino que provoque la convicción de que se trata de un soporte que contiene un mensaje apto para contener y transmitir datos o actos que puedan ser tenidos como ciertos en el ámbito científico y, por ende, en el jurídico" (Vega, 2013: 152).

Aunado con ello, se requiere que el documento sea producto de la actividad humana, al no ser un producto de la naturaleza, los documentos requieren de la participación del hombre para su conformación, en este sentido, "se requiere una exteriorización. Es decir, que el documento sea algo exterior a su autor. En otras palabras, que se concrete en un objeto externo independiente de la mens creatoris" (Vega, 2013: 153). en esta misma línea, al ser un producto de la voluntad humana, el documento requiere de un autor, este, dentro del objeto de estudio de este documento, reviste una especial importancia que se desarrollará más adelante.

Finalmente, siendo el documento un elemento que cuenta con una acepción material y otra ideológica, es claro que no podrá ser considerado como tal en tanto no represente estas dos condiciones. Un documento cuenta con un texto, un conjunto de símbolos y signos que en un idioma determinado expresan una idea concreta, pero además, el documento necesita de la materialidad para existir, todos aquellos símbolos, deben estar plasmados sobre un objeto material. "La existencia del mensaje, como entidad ideal, y del soporte como entidad material, conformando un todo unitario es lo que permite su transmisibilidad" (Vega, 2013: 156).

Pues bien, cuando del concepto se trata, teniendo en cuenta que el enfoque de este estudio está dirigido al derecho penal, es necesario mencionar que el legislador también previó el concepto de documento en el articulo 294 de la Ley 599 de 2000 al tenor de lo siguiente:

“Artículo 294. Documento. Para los efectos de la ley penal es documento toda expresión de persona conocida o conocible recogida por escrito o por cualquier medio mecánico o técnicamente impreso, soporte material que exprese o incorpore datos o hechos, que tengan capacidad probatoria".

\section{Documento público y documento privado}

Habiendo analizado las condiciones del documento en general, es tiempo de adentrarse en el concepto de documento público y documento privado, para así poder desarrollar de mejor forma su relación con la función probatoria y 
por su puesto, con los tipos penales de falsedad previstos en el ordenamiento penal colombiano.

En este sentido, el doctor Jairo Parra Quijano en su Manual de Derecho probatorio advierte frente al tema:

"De conformidad con el articulo 251 del $C$ de P.C., es documento público el otorgado por el funcionario público en ejercicio de su cargo o con su intervención. Si es un escrito, se denomina instrumento, cuando es otorgado por un notario o quien haga sus veces y ha sido incorporado en el respectivo protocolo, se denomina escritura publica. Los demás, son documentos privados" (Parra, 2012: 156)

Y continúa el maestro Parra Quijano advirtiendo:

"En el Código de Procedimiento Penal (Decreto 2700 de 1991) no fue incluida la clasificación de los documentos públicos y privados, lo cual de ninguna manera significa que no exista, pues se trata de una clasificación de gran utilidad para la aplicación del derecho sustancial v.gr., para la estructuración de los delitos descritos en los artículos 218 y 221 del C.P., se desprende de lo anterior que las clasificaciones y sus conceptos han quedado a criterio de la doctrina y la jurisprudencia. (arts. 286 y 287 Ley 599 de 2000)." (Parra, 2012: 156)

Del mismo modo, el doctor Francisco Bernate Ochoa en su obra titulada "Delitos de Falsedad en Estados Financieros, se refiere al tema advirtiendo que:

"El documento puede ser publico o privado. El documento público será el expedido por un funcionario estatal en ejercicio de sus funciones $y$ por exclusión; y el documento privado será todo lo que no es documento público" (Bernate, 2007: 75).

Pero no solo la doctrina se ha ocupado de pronunciarse respecto de unos y otros, a su turno, la Corte Suprema de Justicia en sentencia de Casación del 19 de octubre de 1978, se ocupó de los documentos públicos advirtiendo que:

"En nuestra legislación no ocurre como en otras que la facultad de expedir documentos públicos está reglamentada en el sentido de que solo aquellos funcionaros o empleados, a quienes la ley otorga expresamente la potestad de certificación, esto es, atribuye la función de dotar de la calidad de publico a los escritos que elaboran, pueden expedir esta clase de documentos.

El sistema colombiano es el de que todo funcionario que, en ejercicio de sus funciones, deba elaborar un escrito que implique un ejercicio de éstas, lo dota de la calidad de documento público" (Parra, 2003).

Lo anterior ejemplifica como el sistema probatorio colombiano hace parte de aquellos en donde el documento adquiere una calidad especial, por el hecho de haber sido elaborado por una persona que a su vez, reviste de una condiciones singulares, es decir, en Colombia, el documento público será de esta índole sencillamente por el hecho de haber sido suscrito por cualquier funcionario que en ejercicio de sus funciones lo elabore.

Si bien el objetivo de este documento es analizar la relación que existe entre este tipo de documentos con la función probatoria, se hace imperativo resaltar que:

"los documentos públicos no tienen entonces ni más ni menos fuerza probatoria que otros documentos, puesto que cada documento es un medio para ser analizado valorado por lo que él representa o declara en su objetividad perceptible, independiente de que su origen sea estatal u oficial o simplemente privado. Al respecto vale recordar que: "el hecho de que un documento sea público o privado no demuestra más de lo que intrínsecamente contiene y en ese orden de ideas podrían ser iguales sus alcances probatorios" (Corredor, 2007: 139). 
Frente a los documentos privados, es muy poco lo que se enfatiza, generalmente suelen catalogarse a través de un criterio residual, siendo privados todos aquellos que no sean públicos. No obstante, esta definición resulta del todo incompleta y deficiente, por tal motivo, es necesario determinar de una manera más amplia que se entiende por documento privado, se ha dicho entonces que:

"En principio, el documento privado carece de valor entre las partes y no es oponible a terceros, a menos que sea autentico, recordando que se mantiene el criterio tradicional: Documento privado es el que no reúne los requisitos para ser documento público (...)

al igual que ocurre con la escritura publica, si en el documento privado se plasman contratos y, en general, se contraen obligaciones, su fuerza vinculante solo opera entre quienes fueron parte y sus sucesores, a titulo singular o universal, sin obligar a los terceros, porque ellos no fueron parte del contrato" (Corredor, 2007: 63 y 64).

Entendiendo entonces la diferencia entre uno y otro, es posible sustraer cómo cada uno de estos sin importar de donde emane, cumple una función determinante para quien lo utiliza, específicamente, teniendo en cuenta el objeto de estudio de este escrito, es necesario hacer alusión a la función probatoria que tienen los documentos.

\section{La función probatoria}

Previamente se indicó que el documento tiene una serie de funciones para lo cual es creado; además de las ya mencionadas, el documento debe cumplir con una labor de perpetuidad:

"en la medida en que representa una labor intelectual de su creador que quiere perpetuar su conocimiento, para que haya documento el mismo debe provenir de una persona conocida o conocible, a quien pueda ser atribuido el contenido del documento, pues solo así cumplirá el instrumento su función de garantia”. (Bernate, 2010: 87).

De lo anterior se deriva una segunda función del documento, en este orden de ideas:
"tenemos que de la función de garantía no solo se desprende la necesidad de que el documento provenga de persona conocida o conocible - a la cual se le pueda atribuir el contenido del documento- sino que es necesario que el mismo contenga una declaración de voluntad, es decir, que el contenido busque generar un efecto entre quienes acceden a su contenido" (Bernate, 2010: 90).

Finalmente, el documento cuenta con la función de mayor incidencia para el tema planteado en este estudio, es decir, la función probatoria. Nuevamente recurriendo a las palabras del doctor Bernate Ochoa, se indicó que:

\begin{abstract}
"la tercera función del documento es la función de prueba, en virtud de la cual es necesario, como su nombre lo indica, que el documento pueda servir de prueba. Esto significa que el documento debe tener la eficacia de acreditar algo diferente a su propia existencia, aunque hay que dejar en claro que el documento en sí mismo no prueba la veracidad de la declaración sino solamente la existencia de ella" (Bernate, 2010: 97)
\end{abstract}

Con el pasar de los años, se ha concebido el documento como el medio idóneo para probar un hecho, basta con remitirse a unos pocos años y recordar cómo - en lo que respecta al derecho penal -, el documento era la herramienta por excelencia que guiaba el proceder de la justicia. En un sistema inquisitivo como el que imperaba en Colombia hasta hace una década, el documento era sin duda el medio probatorio preferido dentro de los procesos penales. Hoy en día, pese a los grandes avances de la ciencia y 
a la incursión de nuevas tecnologías dentro del sistema acusatorio, el documento sigue siendo una parte fundamental dentro de los medios probatorios utilizados en las salas de audiencias.

Por tanto, la función probatoria del documento quizás se característica de mayor connotación, teniendo en cuenta que:

"la fuerza probatoria es el mérito que el juzgador encuentra en el documento para formar su convicción; desde ese punto de vista el documento prueba frente a todos, entre las partes y frente a terceros" (Parra, 2003: 58).

No obstante es importante advertir que el documento, una vez se ha puesto a disposición de un proceso, en este caso de un proceso penal, cumple con dos calidades determinantes. El documento tiene la virtud de servir como objeto y como medio de prueba, lo que implicará que se aprecie de manera diferente de conformidad con su función. Frente a este aspecto ha señalado la corte:

"Esindispensablehaceruna nítida diferencia entre el documento público o privado, como medio de prueba y el documento como objeto de prueba en cuanto constituye el objeto material del delito de falsedad documental. Como medio de prueba para acreditar la existencia de una situación jurídica o la creación, modificación o extinción de relaciones relevantes para el derecho, debe estar sometida a las reglas contempladas en el ordenamiento procesal civil y su valor probatorio será el que le atribuyan las disposiciones de dicho ordenamiento.

Como objeto de prueba en la media en que constituye elemento del delito de falsedad, debe merecer el mismo tratamiento que los demás elementos del hecho punible, frente a los cuales existe libertad probatoria, de conformidad con lo preceptuado en el articulo 336 del C. De P.P." (Corte Suprema de Justicia, Sala Penal. 15 de Octubre de 1986).

De manera diáfana, la función probatoria del documento ha servido de antesala para resaltar la relación que existe entre esta y los delitos de falsedad documental. En un primer plano, al revisar los cuatro primeros artículos del Capitulo Tercero de la Ley 599 de 2000, puede observarse lo siguiente:

"Artículo 286. Falsedad ideológica en documento público. El servidor público que en ejercicio de sus funciones, al extender documento público que pueda servir de prueba, consigne una falsedad o calle total o parcialmente la verdad, incurrirá en prisión de cuatro (4) a ocho (8) años e inhabilitación para el ejercicio de derechos y funciones públicas de cinco (5) a diez (10) años.

Artículo 287. Falsedad material en documento público. El que falsifique documento público que pueda servir de prueba, incurrirá en prisión de tres (3) a seis (6) años.

Si la conducta fuere realizada por un servidor público en ejercicio de sus funciones, la pena será de cuatro (4) a ocho (8) años e inhabilitación para el ejercicio de derechos y funciones públicas de cinco (5) a diez (10) años.

Artículo 288. Obtención de documento públicofalso. El que para obtener documento público que pueda servir de prueba, induzca en error a un servidor público, en ejercicio de sus funciones, haciéndole consignar una manifestación falsa o callar total o parcialmente la verdad, incurrirá en prisión de tres (3) a seis (6) años. 
Artículo 289. Falsedad en documento privado. El que falsifique documento privado que pueda servir de prueba, incurrirá, si lo usa, en prisión de uno (1) a seis (6) años". (Énfasis suplido)

De los apartes resaltados es posible establecer que todos los tipos penales aquí previstos cuentan con ingrediente normativo en común, en todos, es necesario para su configuración que el objeto material del delito, en este caso el documento, pueda servir de prueba; este elemento especial reviste una incidencia importante en lo que atiene al bien jurídico tutelado y a la relación que aquí pretende resolverse.

Como es bien sabido, los tipos penales de falsedad documental buscan tutelar el bien jurídico fe pública, pese a las interminables discusiones y teorías en torno a establecer cual es el bien llamado a tutelar, en Colombia el legislador enmarcó los delitos de falsedad documental dentro del bien jurídico fe pública. Si bien el asunto no ha sido pacifico, vale la pena recordar lo siguiente:

"Al parecer, la expresión "fe pública" se le deba a Filangieri, pero el concepto que maneja nuestro Código Penal se aproxima a lo que por la misma entendió Carrara, que influyo la legislación italiana de la época y que, como es sabido, nutre nuestra legislación. (...)

Carrara encuentra que la fe pública se encuentra ligada a la potestad del creador de los documentos, en concreto, a la idea del Estado como creador del documento que emanada de la fe pública. En efecto, Carrara entendía que es una necesidad del hombre creer en otras personas o en determinados signos, valores u objetos" (Bernate, 2010: 23).

Sin duda el concepto de fe pública lleva inmerso un muy alto grado de confianza, en el entendido que a la luz de los documentos, bien sea públicos o privados, quienes hacen uso de ellos estiman que estos responden a una circunstancia cierta y fiable; en especial, cuando se trata de temas probatorios, el colectivo social tiene una confianza legitima en que dichos medios de prueba son verídicos, pues ya hacen parte de un trafico jurídico en donde han podido ser refutados, tachados o verificados por diferentes instancias.

\section{Problemáticas adicionales}

Habiendo enunciado lo anterior y haciendo énfasis en el tema de los tipos penales de falsedad, es importante hacer una precisión respecto de otro de los debates que se ha suscitado a raíz de estos delitos: su momento de consumación. Muchas han sido las contiendas jurídicas que se han llevado a cabo para definir si los delitos de falsedad documental surgen a la vida jurídica desde el mismo momento de la elaboración del documento falaz, o desde cuando este entra a hacer parte del transito jurídico. Al respecto, el doctor Bernate Ochoa ha indicado que "este delito se consuma, no como lo entiende la corte suprema de Justicia con la suscripción del documento, sino con su efectiva introducción en el tráfico jurídico" (Bernate, 2011).

Más allá de la relación causal que existe entre la elaboración del documento faltando a la verdad real o a la verdad material y la configuración del delito de falsedad documental, es necesario analizar la situación a la luz de la teoría de la imputación objetiva, en este sentido es posible determinar que:

"No basta -como lo entiende la corte suprema de Justicia- con la existencia de un documento ideológicamente falso, elaborado por un servidor público en ejercicio de sus funciones, para la estructuración de este delito, sino que es necesario que el servidor público que cree el documento cuente con capacidad probatoria en el caso concreto. Así mismo, 
consideramos que la simple suscripción del documento no representa aún un escenario de lesividad potencial, sino que el reato bajo análisis se consuma en el momento en que el documento se introduce al tráfico jurídico" (Bernate, 2011: 22).

Siguiendo esta línea, es claro que al introducir un documento como medio de prueba, sin considerar su calidad de publico o privado, éste entra a hacer parte del trafico jurídico y por tanto, se ve reflejada claramente la relación que existe entre estos documentos, la función probatoria y los tipos de falsedad documental, pues en este sentido, al incorporarse como tal, se estará configurando alguno de los delitos previstos en el Capitulo Tercero.

Continuando con su estudio y en relación con los delitos estudiados, puntualmente para el caso respecto del delito de falsedad ideológica en documento privado, este doctrinante afirma:

"Como una suma de esta argumentación, la corte señala que son requisitos para la configuración del delito de falsedad ideológica en documento público, los siguientes:

i. Ostentar la calidad de servidor público,

ii. la expedición de un documento público que pueda servir de prueba

iii. que desarrolle la conducta, esto es, que en él se consigne una falsedad o $o$

total o parcialmente la verdad, o lo que es lo mismo, que contenga declaraciones mendaces. Se desarrolla este punto, cuando se indica que "la falsedad se considera ideológica porque el documento no es falso en sus condiciones de existencia y autenticidad, sino que son mentirosas las afirmaciones que contiene. iv. en punto del contenido del dolo, indica la corte, con apoyo en el fallo del 23 de

junio de 2010, que para la estructuración de este delito "no se exige la acreditación de una motivación especial, o un provecho, como si se tratara de un ingrediente subjetivo, sino que el mismo se agota, en sede de tipicidad, con el conocimiento de los hechos y la voluntad, y en el escaño de la culpabilidad, con el conocimiento de la antijuridicidad del comportamiento, esto es, "reside en la conciencia y voluntad de plasmar en su condición de funcionario público y persona imputable, hechos ajenos a la verdad.

v. el documento debe contar con capacidad de prueba, esto es, estar en condiciones de "servir de prueba por atestar hechos con significación jurídica o implicantes para el derecho, es decir que el elemento falsificado debe estar en posibilidad de hacer valer una relación jurídica" (Bernate 2011).

De lo anterior se colige que, no solo para el delito de falsedad ideológica en documento público, sino para el resto de tipos penales que encuentran relación con la falsedad documental, se configura una relación en materia probatoria, pues se parte del hecho que el documento falso está haciendo valer una relación jurídica o probatoria partiendo de una información que no corresponde a la realidad y por lo tanto se está vulnerando la fe pública y la confianza impuesta en tal documento.

De cara a un análisis que perfectamente podría estudiarse en sede de tipicidad, por cuanto se estaría buscando adoptar la conducta reprochable a la estructura normativa y desde un enfoque que a todas luces reviste tintes de un funcionalismo radical, es válido afirmar que la falsificación del documento: 
"no estriba en la inveracidad del contenido sino en el acto de colocar la firma del autor sin la responsabilidad que le corresponde normativamente en el tráfico general. La ausencia de responsabilidad cuando se suplanta un rol se deriva del hecho evidente de que carece de la posición social que se lo permite, pues el problema no es de la firma natural, sino de la falsa configuración objetiva de un autor supuesto al introducir un documento no autentico conforme a los roles predeterminados de configuración de la vida social" (Corredor, 2007, 328).

Finalmente, a modo de conclusión es posible sostener que existe una evidente relación entre los documentos públicos y privados y su función probatoria, conlos delitos de falsedad documental, en el sentido en que estos están previstos como un medio idóneo para la constatación de realidades plasmadas mediante símbolos y signos sobre un objeto material, que logra ser incorporado a un proceso o a la vida jurídica con una finalidad que bien puede ser, probar algo o dar consonancia a un hecho; una alteración de estas realidades, consecuencialmente alterará la verdad que se busca obtener a través de la justicia y por tanto, no solo configurará alguno de los delitos previstos en el Capitulo Tercero, sino que además logrará defraudar la confianza y la fe pública que le subsiste a quienes hacen uso del documento.

Tal y como se vio a lo largo del presente escrito, una de las funciones de mayor relevancia que tienen los documentos es la de probar, en otras palabras, en muchas ocasiones los documentos tienen la virtualidad de salirse de sí mismos y poder probar un hecho. No obstante, cuando el contenido de estos objetos es alterado material o ideológicamente, casi por un efecto dominó, se está alterando la apreciación que el destinatario del mismo pueda darle. Un documento que falte a la verdad o que haya sido alterado por el actuar del hombre, podrá enmarcarse en aquellos documentos previstos en el Capitulo Tercero de la Ley 599 de 2000, pues su función probatoria ya no evidenciará una circunstancia cierta, sino aquella mentira que haya sido reproducida en el, alterando claramente las consecuencias que de este puedan derivarse.

La relación de estas figuras puede presentarse como una cadena: un documento (publico o privado), una función probatoria prevista por el mismo tipo penal, la alteración (material o ideológica) del documento, la incorporación del mismo al trafico jurídico y, la consecuencial y paralela alteración de la confianza o la fe pública con la configuración de los delitos de falsedad documental. Esta concatenada secuencia demuestra que en efecto existe una relación entre todos los elementos aquí enunciados y que se fundamenta en la función probatoria que tienen los documentos y como estos al ser alterados logran alterar el tráfico jurídico al faltar a la verdad.

\section{Referencias}

Arenas, j. (2015). Delito de falsedad. Cuarta edición. Bogotá. Ediciones doctrina y ley.

Bacigalupo e. (1999). El delito de falsedad documental. Editorial madrid. Dykinson.

Bernate, f. (2011). Apuntes sobre el delito de falsedad ideológica. A propósito del fallo del 16 de marzo de 2011 emanado de la corte suprema de justicia, sala de casación penal. Bogotá. Editorial universidad del rosario,

Bernate, f. (2010). Delitos contra la fe pública. Bogotá. Editorial universidad del rosario.

Bernate, f. (2007). Delitos de falsedad en estados financieros. Bogotá. Editorial universidad del rosario. 
Cancio, a. (1981). La falsedad documental. Su evolución y principales modificaciones en el nuevo código penal. Bogotá. Editores jurídicos asociados.

Castro, c. (2012). Derecho penal parte especial. Tomo ii. Bogotá. Editorial universidad del rosario

Corredor, m. (2007). Falsedad documental: ficción social del autor. Bogotá. Editorial universidad externado de colombia.

Irureta, j. (1992). La falsedad documental (delitos de falsificación documentaria). Bogotá. Editora jurídica de colombia.

Jakobs, g. (2011). Falsedad documental. Madrid. Editorial pows marcial.

Martínez, a. (1995). Delitos de falsedad y fraude. Segunda edición. Bogotá. Ediciones librería del profesional.

Martos, f. (2005). Auxiliares administrativos del cabildo insular de gran canaria. Segunda edición. Madrid, ed. Mad s.l.

Montenegro, c. (1982). Delitos contra la fe pública. Bogotá. Augusta impresores.

Parra, j. (2003). Tratado de la prueba judicial. Los documentos. Tomo iii - tercera edición. Bogotá. Librería ediciones del profesional ltda.

Parra, j. (2012). Manual de derecho probatorio. Bogotá. Librería ediciones del profesional ltda.

Vega, j. (2013). El documento jurídico. Problemas de la electronificación. Revista de estudios económicos y empresariales. Núm. 25, 2013, pp. 145-192 - issn: 0212-7237
Código orgánico integral penal de la república del ecuador. Registro oficial suplemente no. 180 de 10 de febrero de 2014

Ley 599 de 2000 (julio 24). Por la cual se expide el código penal. Diario oficial no. 44.037

Ley 906 de 2004 (agosto 31). Por la cual se expide el código de procedimiento penal. Diario oficial no. 45.658 